\title{
Complex Analysis of Car Shredder Light Fraction
}

\author{
B. Vajna ${ }^{1}$, K. Palásti ${ }^{1}$, B. Bodzay ${ }^{1}$, A. Toldy $^{*}{ }^{1,2}$, S. Patachia $^{3}$, R. Buican ${ }^{3}$, C. Catalin $^{3}$ and \\ M. Tierean ${ }^{3}$
}

\author{
${ }^{I}$ Department of Organic Chemistry and Technology, Budapest University of Technology and Economics, H-1111 \\ Budapest, Müegyetem rkp 3, Hungary \\ ${ }^{2}$ Department of Polymer Engineering, Budapest University of Technology and Economics, H-1111 Budapest, \\ Müegyetem rkp 3, Hungary \\ 3 “Transilvania" University of Brasov, Materials Science and Engineering Faculty, 29 Eroilor str., 500036 Brasov, \\ Romania
}

\begin{abstract}
Float fraction of float/sink process of car shredder light fraction was received from RAV (The Netherlands) in the frame of the W2Plastics (http://www.w2plastics.eu/) EU7 project (magnetic sorting and ultrasound sensor technologies for production of high purity secondary polyolefins from waste). The differently coloured plastic waste particles were manually separated and after determining the mass fractions, the particles were analysed by FTIR and Raman spectroscopy. This procedure was repeated also after washing the particles. According to the results the analysed fraction of plastic wastes contained mainly PP and PE, the major large scale contaminants were wood, elastomers and other copolymers. Raman mapping proved to be useful in detecting minor components of polymer waste sample.
\end{abstract}

Keywords: Waste recycling, waste composition analysis, car shredder residue, FTIR spectroscopy, Raman spectroscopy.

\section{INTRODUCTION}

Due to their characteristics, polyolefins (PO) have a wide range of application. One of them is the automotive industry. Polyethylene (PE), especially high density polyethylene (HDPE), is used more often to make containers, lead-acid battery separators, automotive fittings, foams for energy absorption $[1,2]$. PP is used for radiator expansion tanks, brake fluid reservoir fittings, steering wheel covers, wheel arch liner, bumpers, bumper covers, side strips, spoilers, mudguards, battery cases, tool boxes [3]. Also PO derivatives or copolymers, such as trifunctional polypropylene (PP) ether polyol or poly(ethyl-co vinyl alcohol) (EVOH) or poly(ethyl-co-vinyl acetate) (EVA) are largely used in the manufacture of cars.

One of the main disadvantages of the PO-based materials is their non-biodegradability and as consequence, their tendency to accumulate as wastes, creating environmental problems. The end of life cycle properties of PO-s could be changed either by their oxidation, molecular mass decrease or crosslinking, or by modification with additives. The only one way to make recycled polymers to compete the virgin ones is to accurately determine the characteristics of polymeric waste. The quality of the characteristics' determination is a key issue for the success of recycling [4].

Aiming to find new ecological ways to recycle the polyolefinic wastes, the collected polymeric wastes have to be selected to obtain fractions with similar properties. One of

*Address correspondence to this author at the Department of Polymer Engineering, Budapest University of Technology and Economics, H-1111 Budapest, Müegyetem rkp 3, Hungary; Tel: 00361463 2462; Fax: 00361 463 1527; E-mail: atoldy@mail.bme.hu the usual selection methods is based on the polymer's density, but polymeric materials contain also different additives that could modify their densities, making lower the density differences. This way, the yield of separation and its selectivity decreases. Characterization of the obtained fractions is necessary. Their composition in terms of the major components and contaminants is very important both for improving the parameters of the selection process and for determining the recycling possibilities. This task is demanding, due to the material's complexity and to the degradation processes that took place during the life cycle of the polymeric materials.

In the frame of W2Plastics project, our aim was to characterize the polyolefinic mix obtained from shredder automotive waste and separated by float/sink process. The light waste float fraction, coded PC1-ASR, was analyzed.

\section{MATERIALS AND METHODOLOGY}

To reduce the unknown interferences of the additives from the polymeric mixed material such as dies, pigments, fillers, stabilizers, on the analyses results, Transilvania University of Brasov manually separated the particles based on their colour. We noted that the particles are not clean. Consequently, it was difficult to make differences between different particle colours such as white, light brown or grey. To reduce the surface contamination each fraction was washed at room temperature, first with water and detergent and then with Milli-Q distilled water. The washed and dried samples have been selected again. Each fraction was weighted and the percental composition of the mixed PO-s was calculated. After that, each fraction was submitted to FTIR analysis to identify their composition. FTIR spectra were collected with a Perkin-Elmer BX II spectrometer 
equipped with ATR device. Spectral scanned range was 600$4000 \mathrm{~cm}^{-1}$ and spectral resolution was $\sim 2 \mathrm{~cm}^{-1}$.

Budapest University of Technology and Economics performed both Raman point measurements on the differently coloured waste particles, and also Raman mapping of the whole polymer mixture before separation in order to determine its composition.

Raman spectra were collected on a Horiba Jobin-Yvon LabRAM system coupled with an external $532 \mathrm{~nm}$ frequency-doubled Nd-YAG, an external $785 \mathrm{~nm}$ diode laser source and an Olympus BX-40 optical microscope. 10x magnification objective was used for optical imaging and spectrum acquisition. During the spectrum acquisition, the laser beam is directed through the objective, and backscattered radiation is collected with the same objective. The collected radiation is directed through a notch filter that removes the Rayleigh photons, then through a confocal hole and the entrance slit onto a grating monochromator that dispersed the light before a CCD detector. Table 1 summarizes the fixed spectrum acquisition parameters

Table 1. Fixed Spectrum Acquisition Parameters

\begin{tabular}{|l|l|}
\hline Laser: & $\begin{array}{l}\text { frequency-doubled Nd-YAG (532 nm, green light) } \\
\text { diode (785 } \mathrm{nm} \text {, near infrared light) } \\
\text { (selected laser depended on sample fluorescence and } \\
\text { degradation) }\end{array}$ \\
\hline Intensity filter: & $\begin{array}{l}\text { none; } 1 / 2 \text { power; } 1 / 4 \text { power; } 1 / 10 \text { power; } 1 / 100 \text { power; } \\
\text { depending on sample degradation }\end{array}$ \\
\hline Grating: & $\begin{array}{l}1800 \text { groove } / \mathrm{mm}(532 \mathrm{~nm} \text { laser }) \\
950 \text { groove } / \mathrm{mm}(785 \mathrm{~nm} \text { laser })\end{array}$ \\
\hline Spectral range: & $230-1700 \mathrm{~cm}^{-1}$ \\
\hline $\begin{array}{l}\text { Spectral } \\
\text { resolution: }\end{array}$ & $\sim 2 \mathrm{~cm}^{-1}$ \\
\hline $\begin{array}{l}\text { Objective } \\
\text { (magnification): }\end{array}$ & $10 \mathrm{x}$ \\
\hline
\end{tabular}

In case of Raman mapping, the shredded sample was ground in a liquid $\mathrm{N}_{2}$-cooled grinder to reduce the particle size to microscopic scale. The ground particles were pressed with a hydraulic press at 200 bar to provide flat surface for the Raman analysis. Raman mapping was performed using the same instrument described above, using the $785 \mathrm{~nm}$ excitation laser source. The measured area was $24 \times 24$ points with a step size of $500 \mu \mathrm{m} \times 500 \mu \mathrm{m}$ between the adjacent points. The spectrum acquisition time was $3 \mathrm{~s}$ per spectrum. 30 spectra were accumulated and averaged at each measured point to achieve acceptable signal-to-noise ratio.

\section{RESULTS AND DISCUSSION}

\subsection{Gravimetric Analysis}

Table 2 shows the gravimetric repartition of the different coloured fractions before and after particles washing. The obtained results could give information concerning the nonsynthetic polymer contaminants (such as wood) present in the mixed wastes, the major additive used (in our case carbon black) and on the surface contamination degree (dust, oils etc.).
Table 2. Identified Fractions Based on Colour

\begin{tabular}{|c|c|c|c|}
\hline \multirow{2}{*}{ Nr. } & \multirow{2}{*}{ Colour of the Particles } & \multicolumn{2}{|c|}{$(\mathbf{\%})_{\mathbf{w}}$} \\
\cline { 3 - 4 } & & Before Washing & After Washing \\
\hline \hline 1 & Black & 59,05 & 46,31 \\
\hline 2 & Brown & 2,31 & 15,12 \\
\hline 3 & White & 23,23 & 12,61 \\
\hline 4 & Grey & 3,72 & 7,16 \\
\hline 5 & Transparent & 0 & 6,04 \\
\hline 6 & Wood & 3,02 & 3,20 \\
\hline 7 & Red & 2,53 & 2,50 \\
\hline 8 & Blue & 2,21 & 2,48 \\
\hline 9 & Green & 1,78 & 1,90 \\
\hline 10 & Yellow & 1,29 & 1,56 \\
\hline 11 & Orange & 0,73 & 0,96 \\
\hline 12 & Purple & 0,13 & 0,16 \\
\hline
\end{tabular}

As Table 2 shows, 12 fractions have been identified in the initial mixture. A minor fraction of wood has been separated. The major synthetic polymer fraction is black, meaning that the carbon black is the most used filler. The second one is the white fraction that could contain talc and calcium carbonate. The other fractions exhibit a lower frequency. They could contain different classes of organic dies or pigments.

After washing, the percentage of the fractions changed, due to the removal of surface contaminants. A new fraction, a transparent one, could be separated, coming mainly from the initial white fraction. The grey fraction content increased, mainly due to the initially black and white particles. Also the percentage of brown fraction increased after washing, mainly originating from black particles before washing.

\subsection{FTIR Analysis}

More than 50 samples have been analyzed from the selected car shredder waste fractions. At least four samples from each fraction have been submitted to FTIR analysis coded as 1,2,3,4, etc. Their spectra have been compared with the pure PE and PP spectra. It could be noted that both of them show absorption bands in the same range. Two domains of absorption could be identified for PE and PP: one domain at higher wave number in which PE shows two absorption bands at 2843 and $2915 \mathrm{~cm}^{-1}$ and PP shows four superimposed bands with maxima at 2951, 2922, 2863 and $2833 \mathrm{~cm}^{-1}$, respectively. They corresponds to the stretching vibration of $-\mathrm{CH}_{2}$ and $-\mathrm{CH}_{3}$ groups; an other domain in the middle of the analyzed range where PE exhibits one band at $1464 \mathrm{~cm}^{-1}$, while PP exhibits two absorption bands at 1454 and $1377 \mathrm{~cm}^{-1}$, assigned to the bending vibration of $-\mathrm{CH}_{2}$ and $-\mathrm{CH}$ groups respectively.

The band that discriminates better the PE from PP is that from $714 \mathrm{~cm}^{-1}$, present only in PE spectrum corresponding to the skeletal vibration. 
It could be also noted that some of the fractions have quite homogeneous composition. For example, white, blue and green fractions seem to contain only PP, as it is exemplified in (Fig. 1). There could be observed only few signs of the polymer oxidation (very low absorption bands in the range of $1100 \mathrm{~cm}^{-1}$, attributed to $\mathrm{C}-\mathrm{O}$ stretching vibration or at $1730-1740 \mathrm{~cm}^{-1}$, absorption attributed to the $-\mathrm{C}=\mathrm{O}$ carbonylic group stretching vibration, characteristic for aged PO-s).

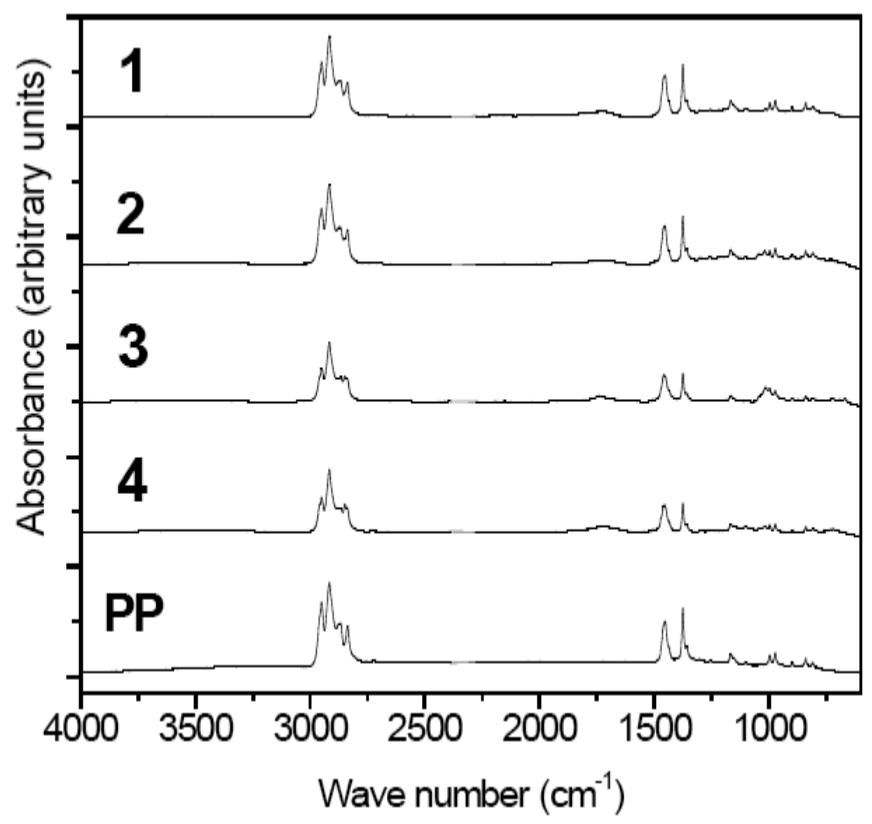

Fig. (1). FTIR spectra of the particles $(1,2,3,4)$ from the blue fraction compared to the spectrum of PP.

Other fractions exhibit a more heterogeneous composition, but most of them have a higher content than $75 \%$ of PP (e.g. transparent, orange, purple fractions). The most complex fraction is the black one, where PE, PP and one elastomer, possible poly(ethylene-co-diene) have been identified, as (Fig. 2) shows.

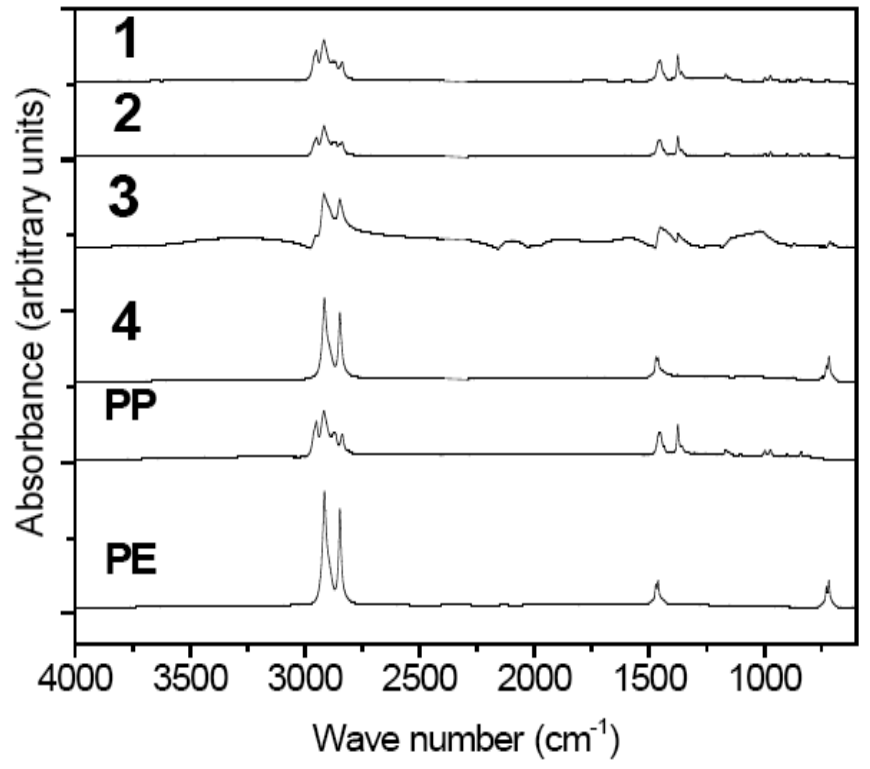

Fig. (2). FTIR spectra of the particles $(1,2,3,4)$ from the black fraction compared to the spectrum of PP and PE.
The other fractions with complex composition are the following: brown fraction where PP, EVA and epoxy resins were identified and yellow fraction that contains PE, oxidized PE, PP and oxidized PP (Figs. 3-5).

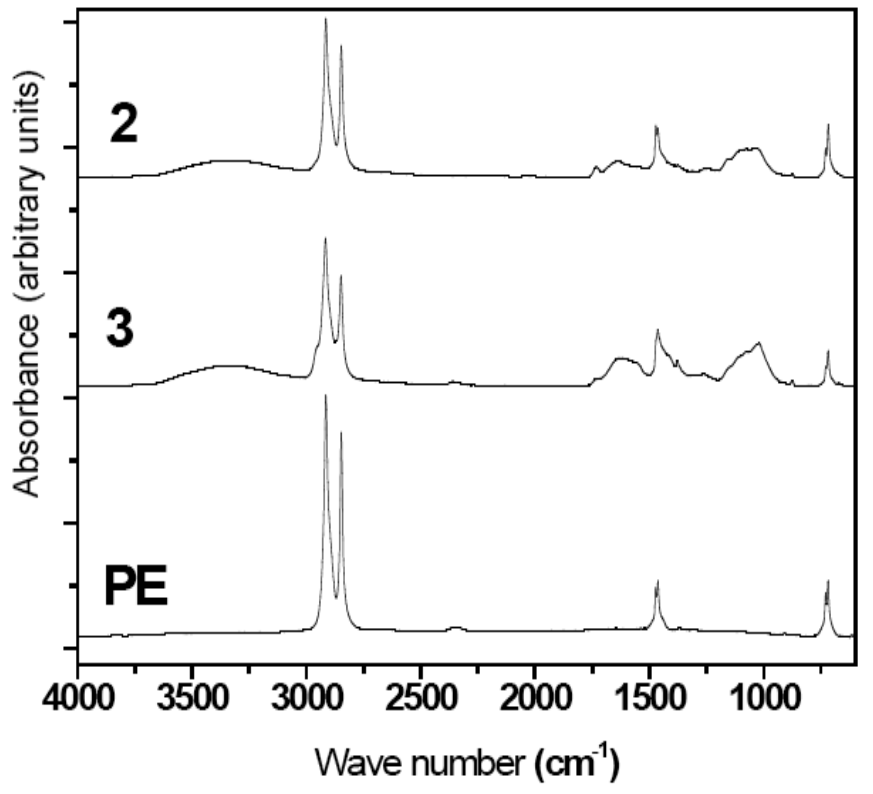

Fig. (3). FTIR spectra of the PE based particles $(2,3)$ from the yellow fraction compared to the spectrum of PE.

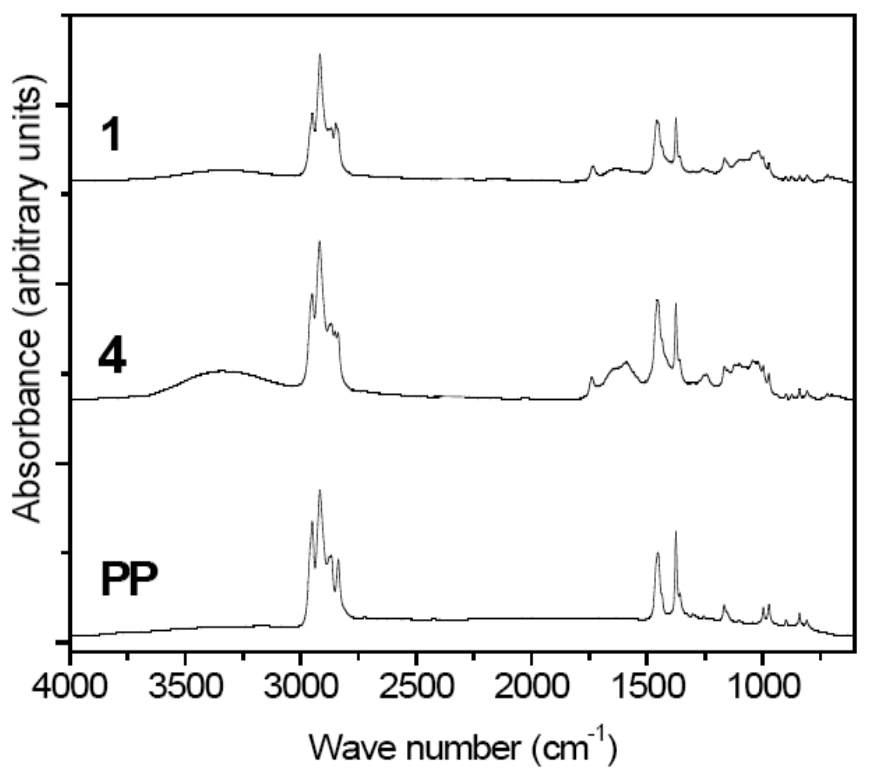

Fig. (4). FTIR spectra of the PP based particles $(1,4)$ from the yellow fraction compared to the spectrum of PP.

The orange sample contains besides PP an elastomer that exhibits a very similar FTIR spectrum to the silicon rubber, but the last one is a minor component, more than $90 \%$ being PP.

Table 3 presents the calculated percents of the synthetic polymers in each fraction, separated by colours from cars shredder wastes.

Taking into account the weight percent of each fraction, determined by gravimetry, and its approximate composition, determined by FTIR, we could make a rough approximation 


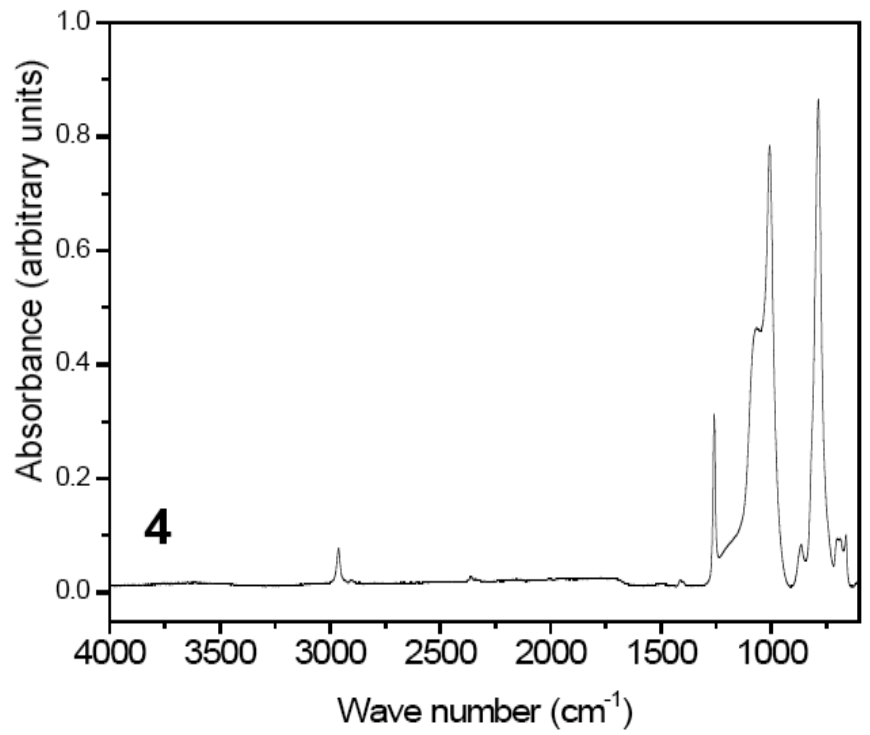

Fig. (5). FTIR spectrum of the elastomer identified as silicon rubber in the orange fraction.

Table 3. Percentage of Synthetic Polymers Identified in Each Fraction Separated by Colours

\begin{tabular}{|c|c|c|c|c|}
\hline \multirow{2}{*}{ Nr. } & \multirow{2}{*}{ Fraction } & \multicolumn{3}{|c|}{$\%$} \\
\cline { 3 - 5 } & & PE* & PP* & Other Polymers \\
\hline \hline 1 & Black & 30 & 50 & 20 \\
\hline 2 & Brown & 10 & 40 & 50 \\
\hline 3 & White & - & 100 & - \\
\hline 4 & Grey & 25 & 75 & - \\
\hline 5 & Transparent & 25 & 75 & - \\
\hline 6 & Red & 30 & 70 & - \\
\hline 7 & Blue & - & 100 & - \\
\hline 8 & Green & - & 100 & - \\
\hline 9 & Yellow & 50 & 50 & - \\
\hline 10 & Orange & - & 90 & - \\
\hline 11 & Purple & 25 & 75 & \\
\hline$*$ Calculated percents took into account also oxidized PE and PP.
\end{tabular}

of the car shredder wastes sample composition. It contains approximately $3 \%( \pm 2 \%)$ of wood, $70 \%( \pm 5 \%)$ of PP, $18 \%$ $( \pm 5 \%) \mathrm{PE}$ and $9 \%( \pm 5 \%)$ of other polymers such as EVA, poly(ethylene-co-diene), silicon rubber and derivatives of polyethylene glycol (PEG). The same percentages are confirmed by the repartition of the correlation coefficient values for each spectrum in comparison with $\mathrm{PE}$ and $\mathrm{PP}$ spectra, respectively. These calculations have been performed by using Essential FTIR software and FDM Library. For low oxidized samples we obtained correlation coefficients higher than 0.9. For oxidized samples we obtained lower coefficients, between 0.66677 and 0.9 , in function of the degree of oxidation.

The main part of the fractions containing PE and PP exhibits signs of the polymer oxidation. The degree of oxidation could be quantified by calculation the carbonyl index (CI). Different suggestions of CI calculation have been done.

For example, carbonyl index (CI), calculated with formula (Eq. 1) is usually used to characterize the oxidation degree of PE-s.

$\mathrm{CI}_{\mathrm{PE}}=\mathrm{A}_{1710} / \mathrm{A}_{1380}$

where $\mathrm{A}$ is the absorption intensity of the IR bands from 1710 and $1380 \mathrm{~cm}^{-1}$, respectively [5].

In case of PP, CI could be calculated as the area of the carbonyl absorption bands $A_{C}$ (occurring in the range from 1700 to $1800 \mathrm{~cm}^{-1}$ ) related to the area of a reference band $A_{R}$ (ranging from 2700 to $2750 \mathrm{~cm}^{-1}$ ) [6].

All the calculation formulas use in fact the ratio of the band intensity of the carbonyl groups and the intensity absorption bands of $-\mathrm{CH}_{2}$ or $-\mathrm{CH}_{3}$ groups, or the ratio of the areas of these bands. In this work, trying to obtain a real image of the oxidation degree of the analyzed polymeric materials, we used as carbonyl index the ratio between the area of the absorption bands situated around 1650 and 1750 $\mathrm{cm}^{-1}$, corresponding to carbonyl groups and the area of the absorption bands situated between 2750 and $2900 \mathrm{~cm}^{-1}$ for PP and the area of the absorption band situated between 1470 and $1460 \mathrm{~cm}^{-1}$ for $\mathrm{PE}$, respectively. The most significant results are presented in Table 4.

Table 4. CI for PE and PP in the Different Selected Car Shredder Fractions

\begin{tabular}{|c|c|c|c|}
\hline Nr. & Sample & CI $_{\mathbf{P E}}$ & $\mathbf{C I}_{\mathbf{P P}}$ \\
\hline \hline 1 & White 1 & - & 0.35 \\
\hline 2 & Green 1 & & 0.49 \\
\hline 3 & Brown 1 & 0.16 & - \\
\hline 4 & Brown 2 & - & 0.22 \\
\hline 5 & Brown 3 & - & 0.29 \\
\hline 6 & Purple 1 & - & 0.99 \\
\hline 7 & Green 3 & - & 0.097 \\
\hline 8 & Yellow 2 & 0.98 & - \\
\hline 9 & Yellow 3 & 1.92 & - \\
\hline 10 & Red 2 & - & 0.12 \\
\hline 11 & Red 3 & - & 0.22 \\
\hline 12 & Transparent 3 & 0.19 & - \\
\hline 13 & Transparent 1 & - & 0.09 \\
\hline 14 & Blue 1 & - & 0.21 \\
\hline
\end{tabular}

Taking into account the gravimetric composition of the mixed automotive shredder wastes and the average CI per fraction, we calculated an average carbonyl index of the mixture as 0.72 . The value is relatively low, mainly due to the fact that the black fraction that is mainly present in the waste sample does not show signs of oxidation. 


\subsection{Raman Analysis}

A large number of particles were measured and chemically identified. The results are classified based on the particle colours. Many particles (of several different colours) were not measurable, because they showed degradation, or because the fluorescent background was so high that no Raman bands were detected.

Among the white particles we mainly found two types, PP (Fig. 6) and PE (Fig. 7). One particle was polycarbonate (Fig. 8).

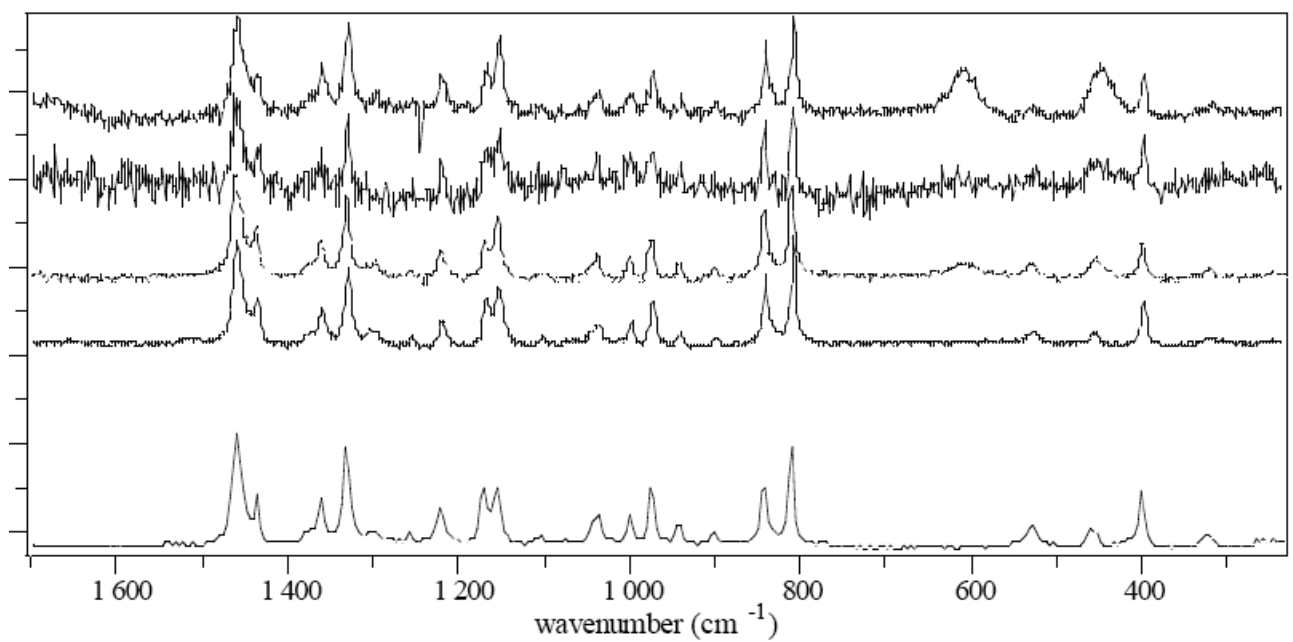

White
particles

PP

Fig. (6). Spectra of white particles consisting of polypropylene.

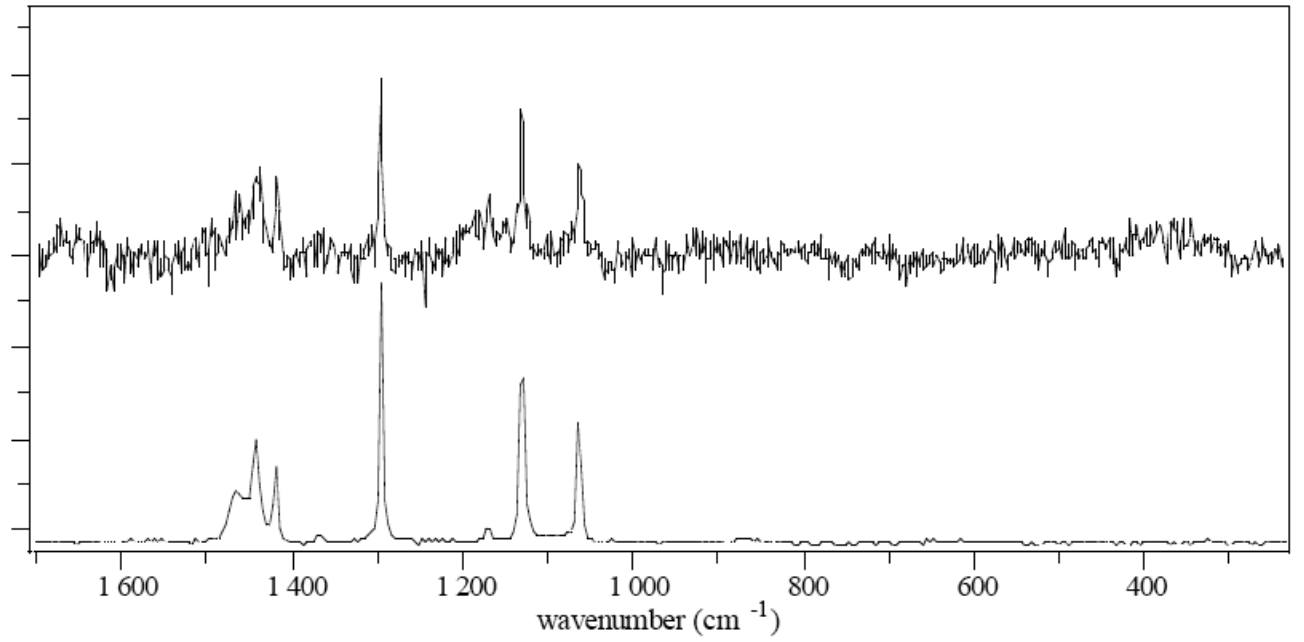

White particles

PE

Fig. (7). Spectra of white particles consisting of polyethylene.

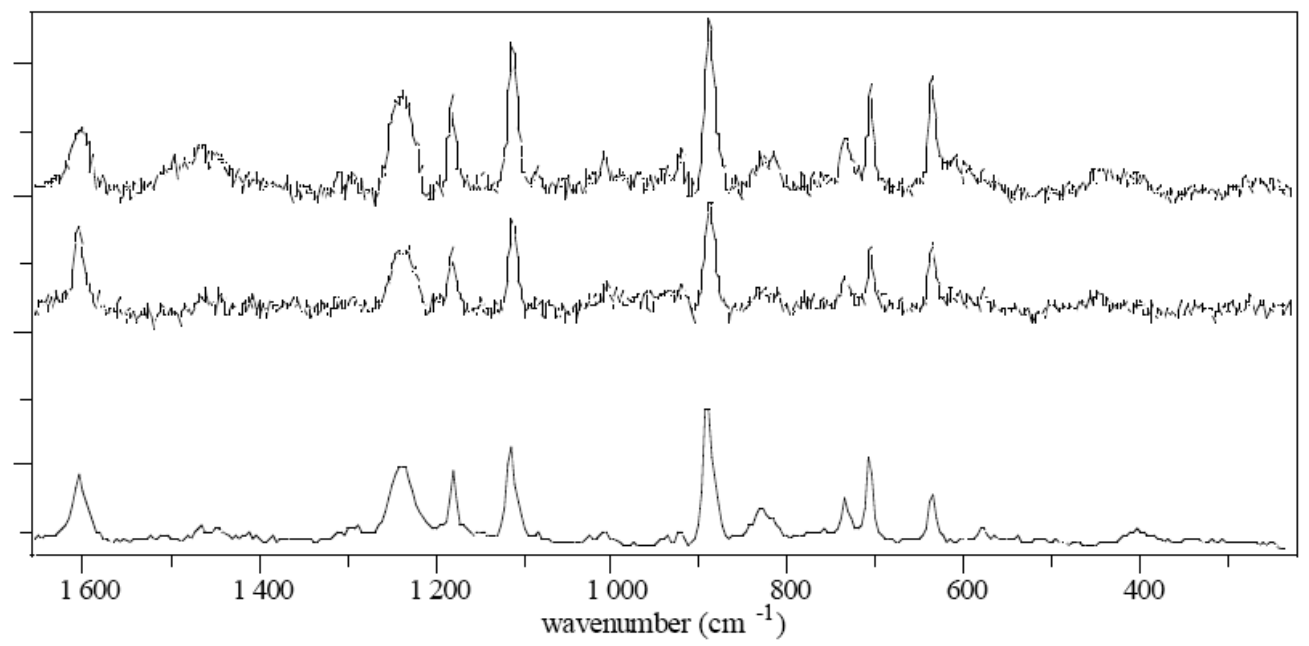

White particles

Fig. (8). Spectra of white particles consisting of polycarbonate. 


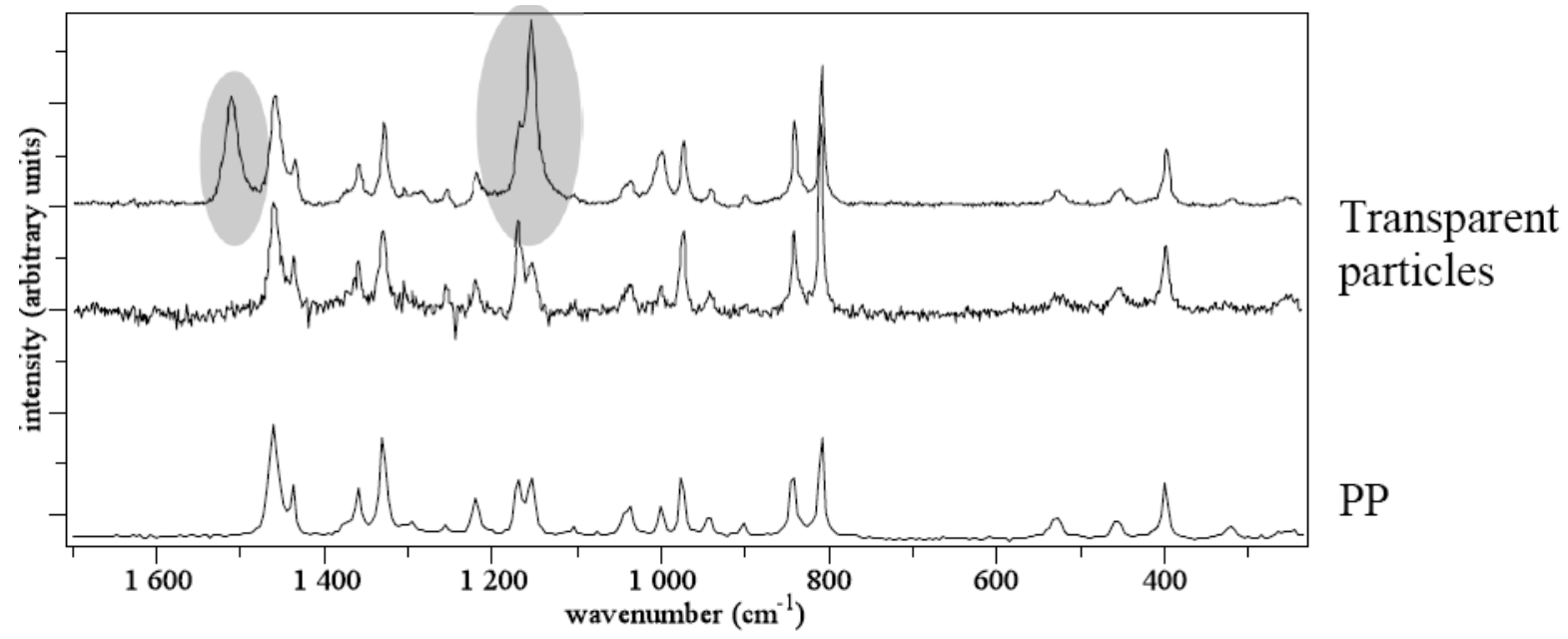

Fig. (9). Spectra of transparent particles consisting of polypropylene.

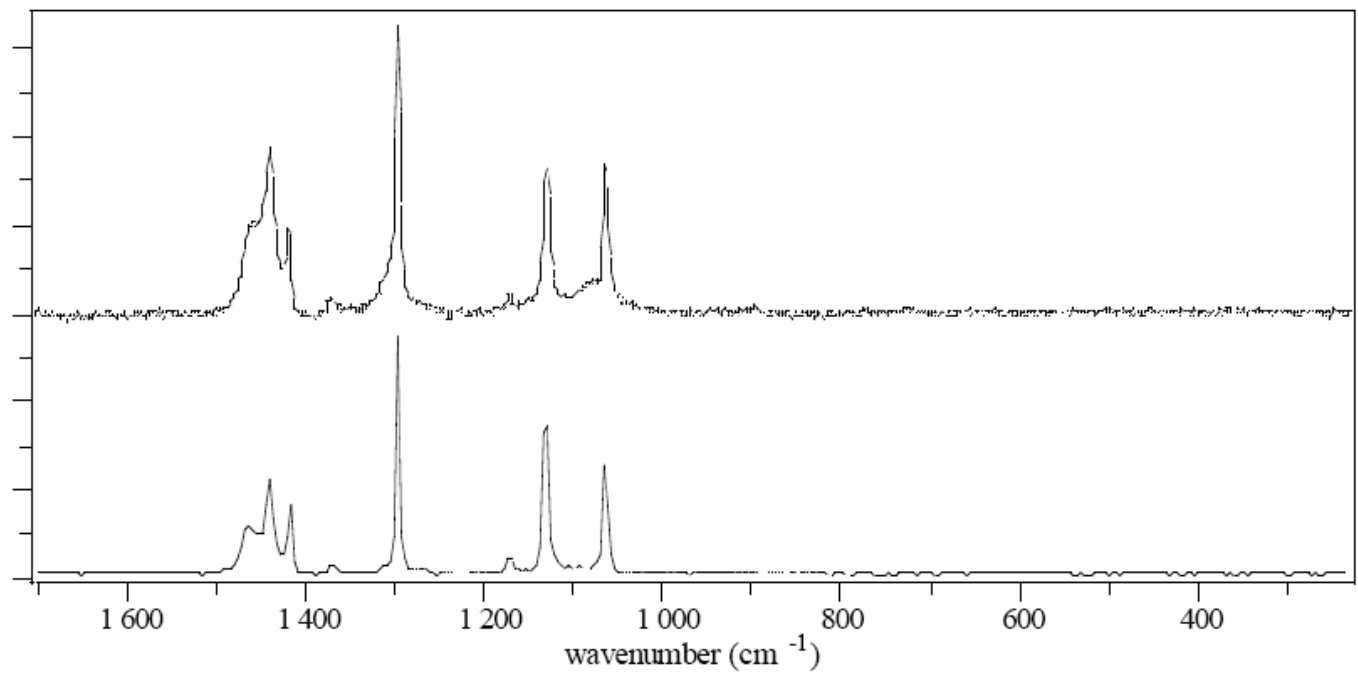

\section{Transparent particles}

$\mathrm{PE}$

Fig. (10). Spectra of transparent particles consisting of polyethylene.

Among the transparent particles we found two types, PP (Fig. 9) and PE (Fig. 10).

The upper spectrum of Fig. (9) shows signs of another component present in the particle. However, unfortunately we did not manage to identify the component.

The black particles consisted of PP (Fig. 11). However, all the spectral bands are widened compared to the reference PP spectrum. This can be caused by an already ongoing

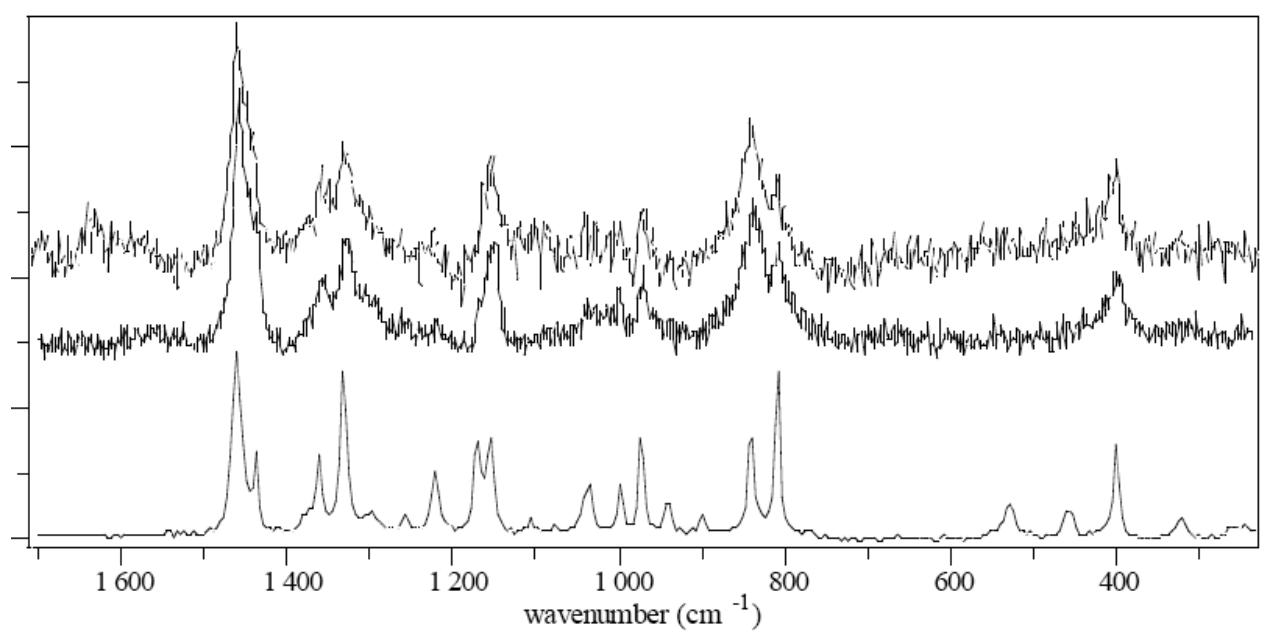

Black particles

Fig. (11). Spectra of black particles consisting of polypropylene. 
degradation process, or by the fact that the PP is amorphous in the investigated particle.

The grey particles consisted of PP (Fig. 12). Besides the PP bands, other signals were observed, which can be due to the colouring agent. (Shadowed area highlights the Raman bands corresponding to the dyes present in the measured sample (i.e. the Raman bands corresponding not to the plastic).

Some particles could not be measured due to sample degradation.

The substance of the measured green particles was PE (Fig. 13). Bands of phtalocyanine-type green dye were also detected.

The substance of the measured blue particles was PP (Fig. 14). Bands of phtalocyanine-type blue dye were also detected. This dye showed similarity to the blue cobalt(II)phtalocyanine dye.

Other type of blue particles was also measured (Fig. 15), where we found a smaller quantity of dye material (it was not even detected everywhere).
Blue particles made of polyethylene were also found (Fig. 16).

The substance of the measured yellow (both transparent and filled yellow) particles was PP (Fig. 17). Dye material was also detected but could not be identified.

The substance of the measured red particles was PP (Fig. 18). Dye material was also detected but could not be identified (spectrum shows some similarity with berberine type dyes). Some red particles only gave fluorescent background, which makes the identification almost impossible.

The majority of purple particles could not be measured. The only particle that gave valuable response signal consisted of polystyrene (Fig. 19). It is possible that numerous purple particles consist of PS, because PS samples usually suffer intensive degradation during exposure to the laser source. The dye present could not be identified.

The brown particles could not be measured under any measurement conditions. We found wooden particles, but those will not be seen with Raman mapping analysis either, because instead of cellulose spectrum we experienced a high level of fluorescent background.

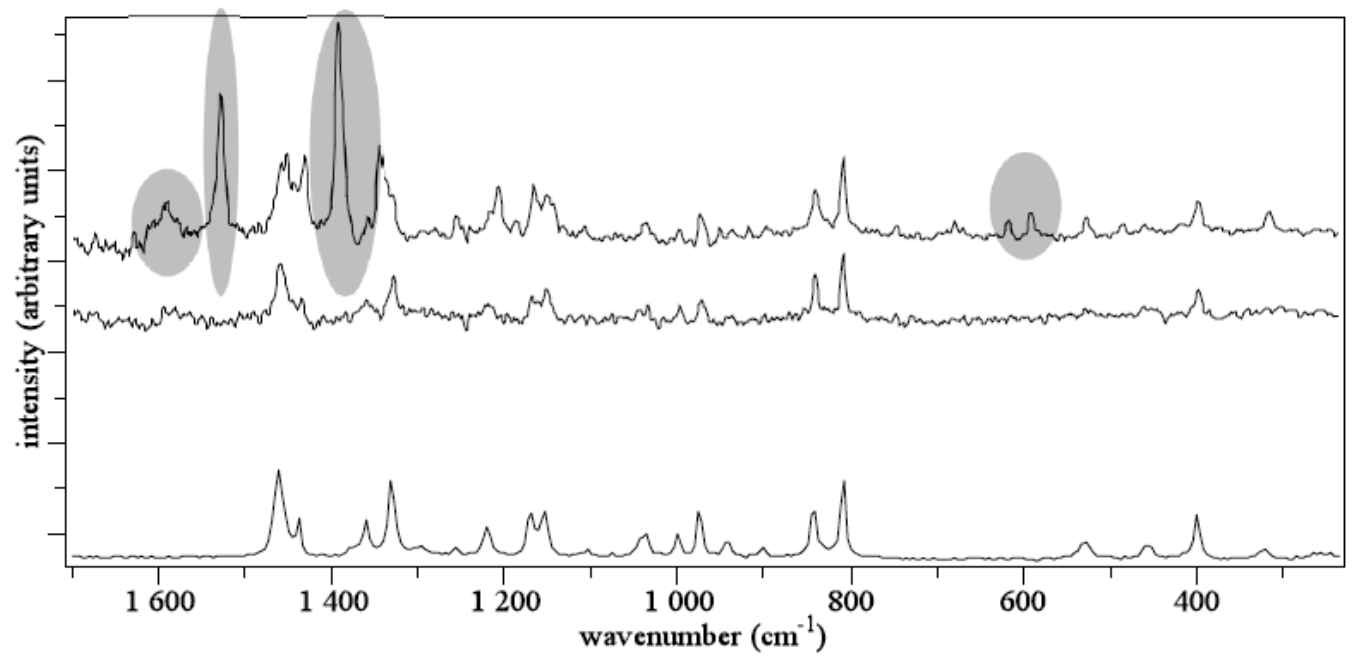

\section{Grey particles}

PP

Fig. (12). Spectra of grey particles consisting of polypropylene.

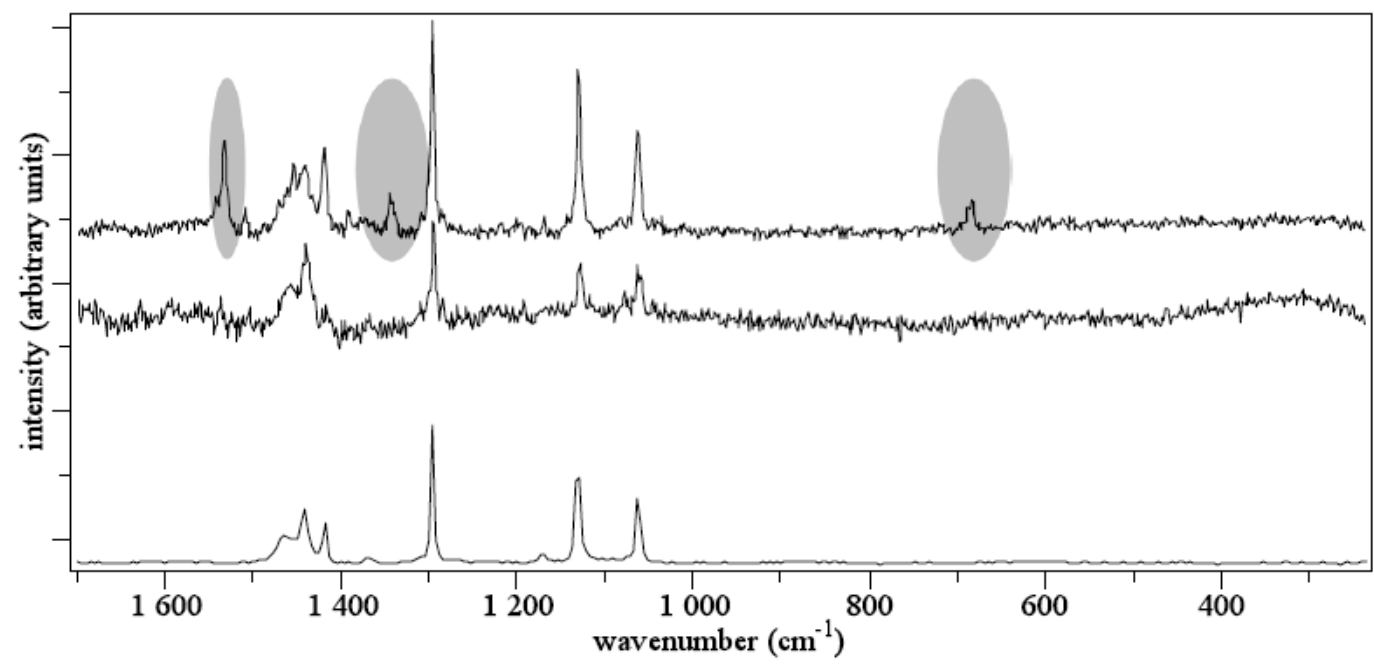

Fig. (13). Spectra of green particles consisting of polyethylene. 


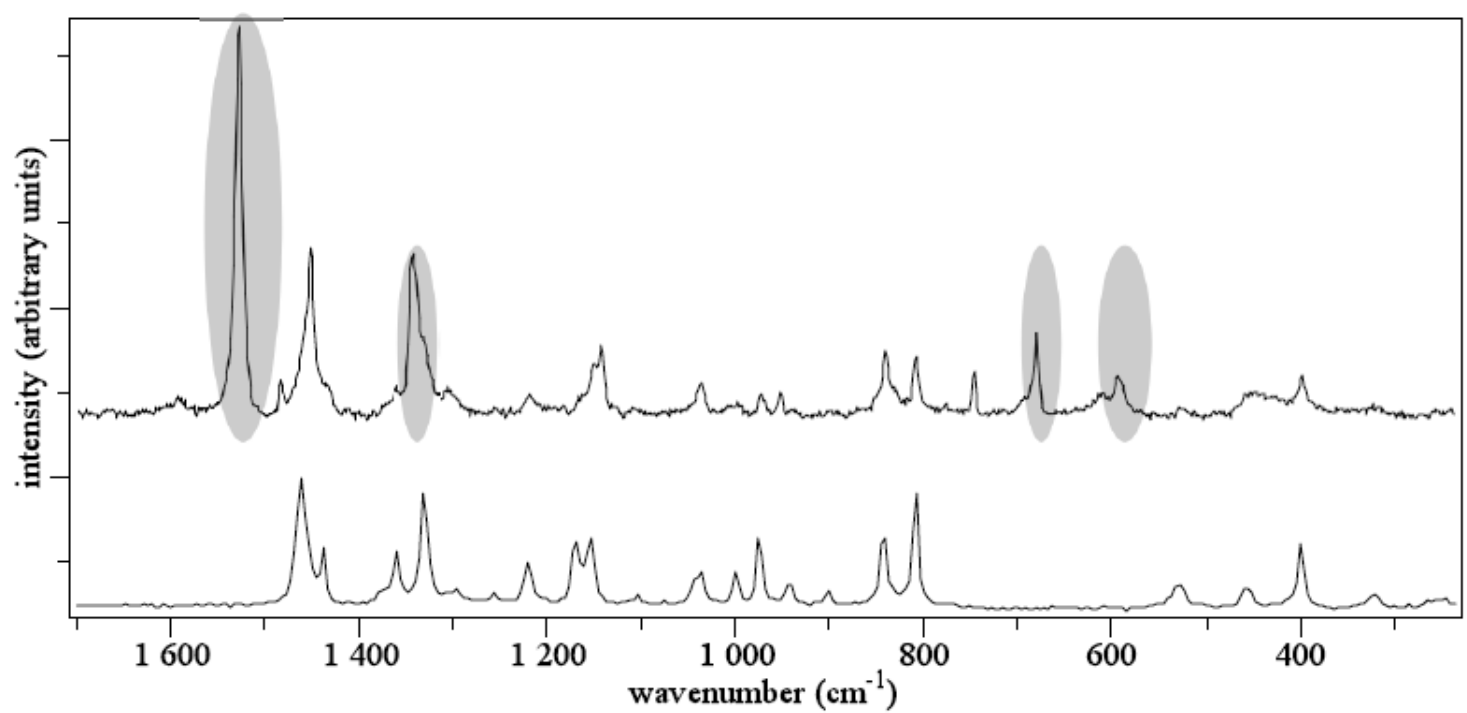

Blue particles

Fig. (14). Spectra of blue particles consisting of polypropylene.

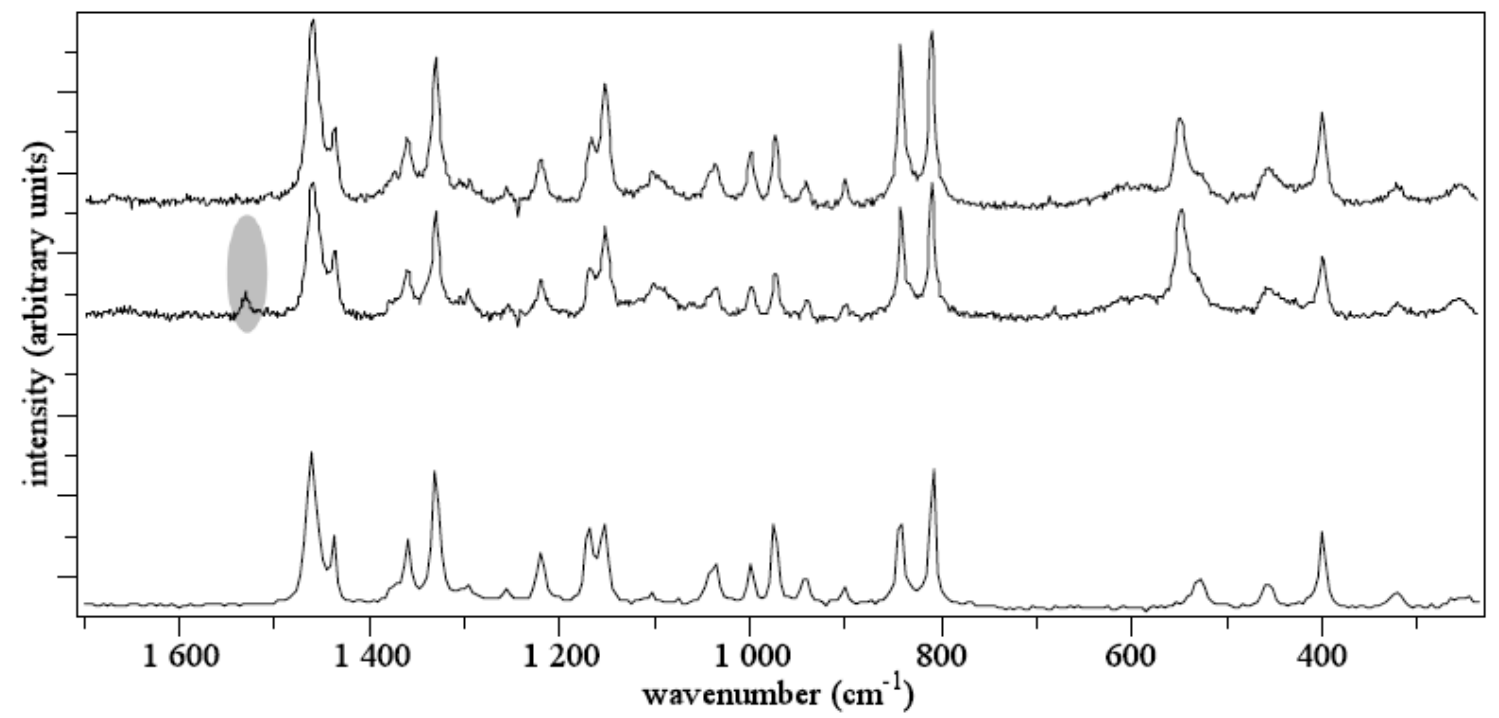

Blue particles

Fig. (15). Spectra of blue particles consisting of polypropylene.

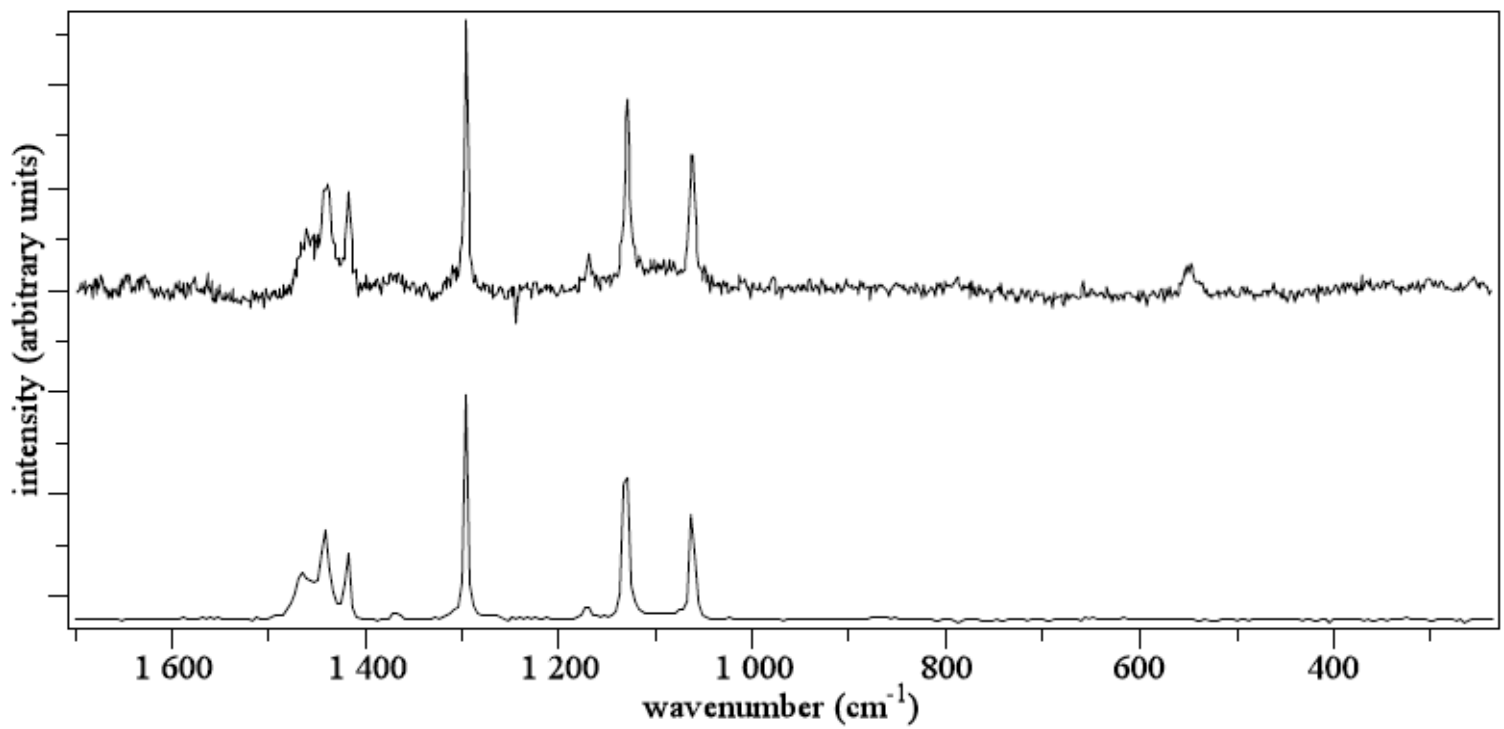

Blue particles

PE

Fig. (16). Spectra of blue particles consisting of polyethylene. 


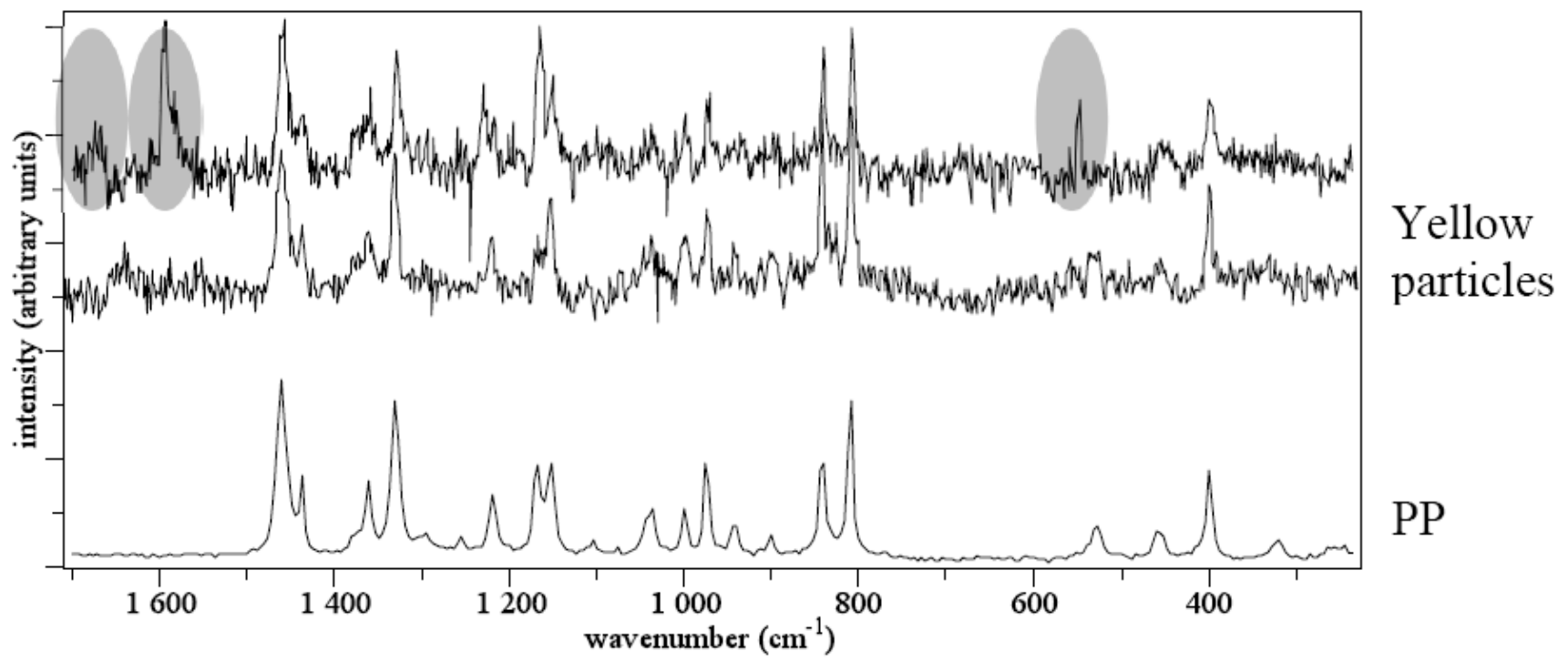

Fig. (17). Spectra of yellow particles consisting of polypropylene.

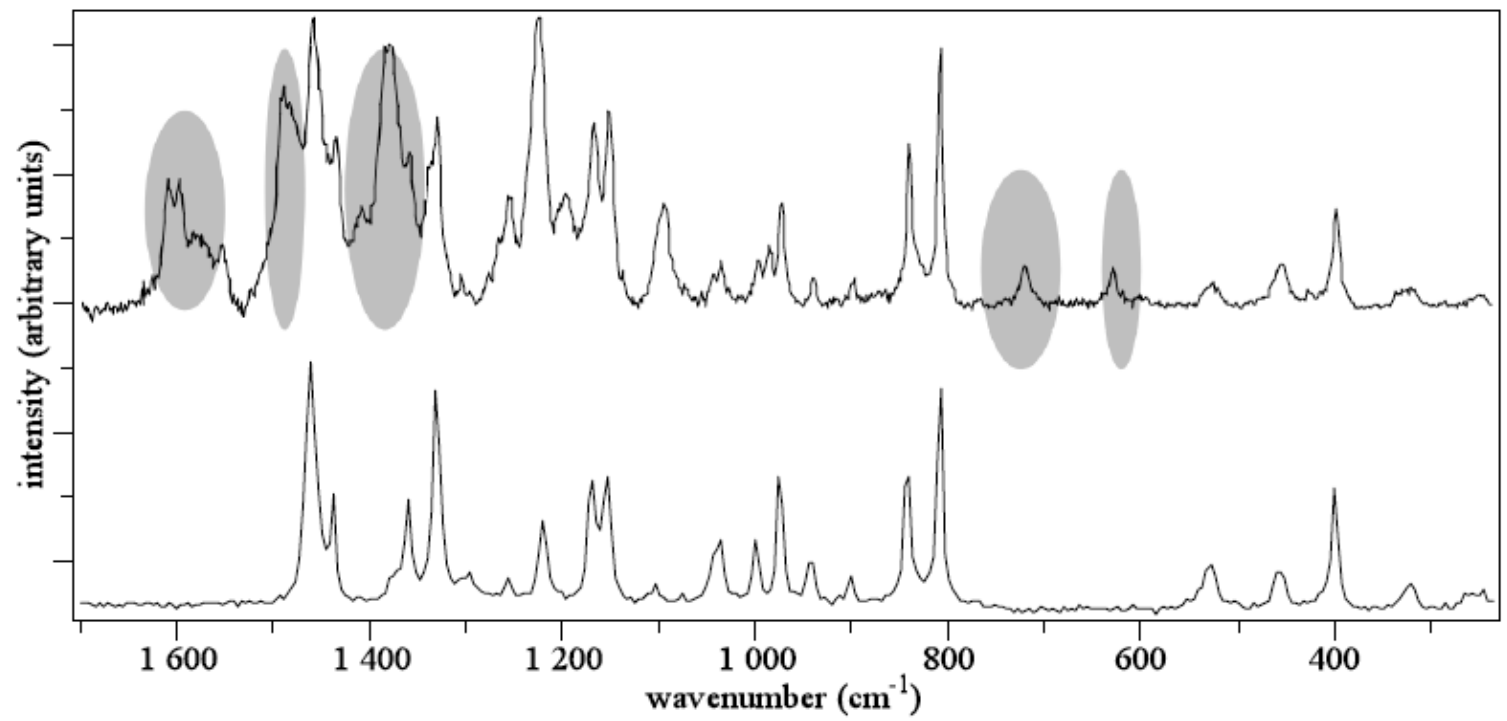

Red particles

PP

Fig. (18). Spectra of red particles consisting of polypropylene.

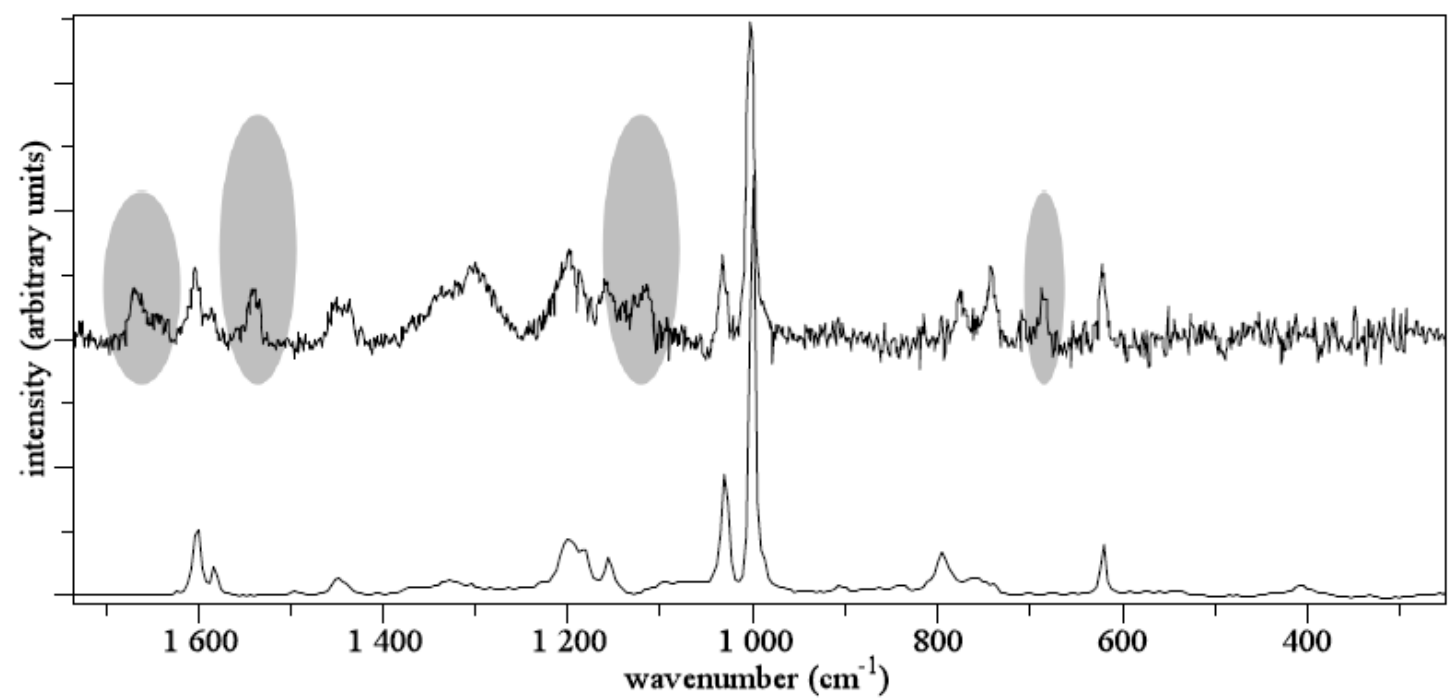

Purple particles

PS

Fig. (19). Spectra of purple particles consisting of polystyrene. 
Table 5. Composition of the Sample Determined by Raman Mapping

\begin{tabular}{|c|c|c|c|c|c|c|c|c|c|c|c|}
\hline PS & PP & PE & PC & PMP & PMMA & PA & cell. & PVAc & POD & PET & Unknown \\
\hline \hline 24.0 & 19.6 & 3.0 & 0.2 & 0.5 & 0.9 & 1.4 & 0.2 & 0.2 & 0.2 & 0.3 & 49.7 \\
\hline
\end{tabular}

Abbreviations applied in Table 5: PS: polystyrene, PP: polypropylene PE: polyethylene, PC: polycarbonate, PMP: polymethylpentene, PMMA: polymethyl metacrylate, PA: polyamide, cell.: cellulose, PVAc: polyvinylacetate, POD: poly(diphenyl-oxadiazole).

\subsection{Results of Raman Mapping}

The quantitative analysis was carried out by inspecting the spectra on the map one by one and identifying the component that has the same spectrum. By counting the number of points containing a particular component, dividing it with the total number of points (576) and multiplying the result with 100 gives the composition in volume percentage. Due to the different sensitivity of the points to the laser treatment, approximately half of the spectra only contain fluorescent background without any Raman bands. As a result, half of the sample could be quantitatively described. Table $\mathbf{5}$ shows the quantitative results.

In order to obtain more reliable quantitative results, a more exact density range would be preferable for Raman mapping to avoid the degradation of the significantly different polymer particles due to the fixed spectrum acquisition time. Nevertheless, Raman-mapping proved to be more sensitive than FTIR in the detection of the minor components in the sample as PC, PMP, PMMA, PA, cellulose, PVAc, POD and PET.

\section{CONCLUSIONS}

FTIR spectrometry is a suitable tool for the characterization the polyolefinic wastes mixtures. FTIR spectra could give information on the major and minor compounds nature and on their ratio into the mixture. Also they allow determining the polymer's oxidizing degree, expressed by Carbonyl Index (CI).

FTIR analysis of the automotive shredder wastes light fraction, collected by SLF-ELV Austria evidenced the presence of approximately $3 \%$ wood, $70 \% \mathrm{PP}, 18 \% \mathrm{PE}$ and $9 \%$ of other polymers such as PEVAc, poly(ethylene-codiene), silicon rubber and derivatives of PEG. The average CI of the mixture is 0.72 . The black fraction shows the lowest degree of oxidation.

Gravimetric determination of the obtained fraction based on colour evidenced that the major fraction is the black one, meaning that the major filler is carbon black and the second one is the white one, meaning that the calcium carbonate, kaolin, $\mathrm{TiO}_{2}$ or $\mathrm{ZnO}$ and talc are present in high amount into the mixture [1,2]. Also taking into account the colours repatition and the mainly used dies or pigments (cobalt blue, Cadmium orange, Cadmium red, Cadmium yellow, Iron oxide, Molibdate yellow, lithopone yellow, lithopone red, quinacridone red pigment), an approximate calculus of these additives ratio could be determined $[1,2]$.

The Raman investigation of the particles shows that the car shredder sample mainly consists of PP and PE, but also contains PC and PS in small amounts. In many particles the bands of the colouring agents were also detected, however, accurate identification was almost never possible due to the large number of dyes with similar spectra.

The automatized Raman mapping leads to different estimation for the composition: this way the main component seems to be PS instead of PP and PE. This shows that with an automated method and fixed spectrum acquisition time the degradation rate is different among the different polymers. However, Raman mapping is very useful in detecting minor components in the sample. In the car shredder sample traces of PC, PMP, PMMA, PA, cellulose, PVAc, POD and PET were also detected.

\section{ACKNOWLEDGEMENTS}

This research was supported by Magnetic sorting and ultrasound sensor technologies for production of high purity secondary polyolefins from waste (W2PLASTICS) EU7 project, Grant Agreement Number: 212782, Elaboration of recycling technologies for non-metallic automotive and electronic wastes avoiding further deposition of organic materials (RECYTECH) Hungarian project, Identification Code: TECH_08-A4/2-2008-0142 and the János Bolyai Scholarship of the Hungarian Academy of Science.

\section{REFERENCES}

[1] C. Vasile and M. Pascu, Practical Guide to Polyethylene, Rapra Technology Limited, 2005.

[2] A. J. Peacock, Handbook of Polyethylene: Structure, Properties and Applications, Marcel Decker Inc. New York, 2000.

[3] D. Tripathi, Practical Guide to Polypropylene, Rapra Technology Limited, 2002.

[4] S. Karlson, "Recycled Polyolefins. Material properties and means for quality determination", Adv. Polym. Sci., vol. 169, pp. 201-229, January 2004.

[5] M. A. Salem, "Mechanical Properties of UV irradiated low-density polyethylene films formulated with carbon black and titanium dioxide", Egypt. J. Sol., vol. 24(2), pp. 141-150, January 2001.

[6] M. Obadal, R. Čermák, J. Výchopňová, M. Raab, V. Verney, S Commereuc and F. Fraïsse, "Photodegradability of $\beta$-nucleated isotactic polypropylene," in 8th Polymers for Advanced Technologies International Symposium, Budapest, Hungary, 2005. 